\title{
Stability, Boundedness, and Existence of Periodic Solutions to Certain Third-Order Delay Differential Equations with Multiple Deviating Arguments
}

\author{
A. T. Ademola, B. S. Ogundare, M. O. Ogundiran, and O. A. Adesina \\ Research Group in Differential Equations and Applications (RGDEA), Department of Mathematics, \\ Obafemi Awolowo University, Ile-Ife 220005, Nigeria
}

Correspondence should be addressed to O. A. Adesina; oadesina@oauife.edu.ng

Received 13 July 2015; Accepted 31 August 2015

Academic Editor: Nikolai N. Leonenko

Copyright (C) 2015 A. T. Ademola et al. This is an open access article distributed under the Creative Commons Attribution License, which permits unrestricted use, distribution, and reproduction in any medium, provided the original work is properly cited.

\begin{abstract}
The behaviour of solutions for certain third-order nonlinear differential equations with multiple deviating arguments is considered. By employing Lyapunov's second method, a complete Lyapunov functional is constructed and used to establish sufficient conditions that guarantee existence of unique solutions that are periodic, uniformly asymptotically stable, and uniformly ultimately bounded. Obtained results not only are new but also include many outstanding results in the literature. Finally, the correctness and effectiveness of the results are justified with examples.
\end{abstract}

\section{Introduction}

Differential equations of second and third order with and without delay are essential tools in scientific modeling of problems from many fields of sciences and technologies, such as biology, chemistry, physics, mechanics, electronics, engineering, economy, control theory, medicine, atomic energy, and information theory. Many authors have proposed different methods, in the literature, to discuss qualitative bahaviour of solutions to nonlinear differential equations. Here, we will single out two methods. In this direction, we can mention Lyapunov's second method which demands the construction of a suitable positive definite function (or functional) whose derivative is negative definite; that is, it involves finding the system of closed surfaces that contained the origin and are converging to it. The second method is the frequency domain technique which involves the study of position of the characteristics polynomial roots in the complex plane to obtain certain matrix inequalities which must be positive.

The qualitative behaviors of solutions of differential equations of third order have been discussed extensively and are still receiving attention of authors because of their practical applications. In this regard, we can mention the works of Burton [1, 2], Driver [3], Hale [4], and Yoshizawa [5, 6] which contain general results on the subject matters and expository papers of Abou-El-Ela et al. [7], Ademola et al. [8-10], Adesina [11], Afuwape and Omeike [12], Chukwu [13], Gui [14], Omeike [15, 16], Sadek [17], Tejumola and Tchegnani [18], Tunç et al. [19-28], Yao and Wang [29], and Zhu [30] and the references cited therein.

Recently, Tunç [27] employed Lyapunov's second method to prove two results on stability and boundedness of nonautonomous differential equations with constant delay

$$
\begin{aligned}
\dddot{x}+ & f(t, x, x(t-\tau), \dot{x}, \dot{x}(t-\tau), \ddot{x}, \ddot{x}(t-\tau)) \\
& +g(\dot{x}(t-\tau))+h(x(t-\tau)) \\
= & p(t, x, x(t-\tau), \dot{x}, \dot{x}(t-\tau), \ddot{x}, \ddot{x}(t-\tau)) .
\end{aligned}
$$

Furthermore, Ademola [9] discussed existence and uniqueness of a periodic solution to the third-order differential equation

$$
\begin{aligned}
\dddot{x} & +f(t, x, \dot{x}, \ddot{x}) \ddot{x} \\
& +\sum_{i=1}^{n} g_{i}\left(t, x\left(t-\tau_{i}(t)\right), \dot{x}\left(t-\tau_{i}(t)\right)\right)
\end{aligned}
$$




$$
\begin{aligned}
& +\sum_{i=1}^{n} h_{i}\left(t, x\left(t-\tau_{i}(t)\right)\right) \\
& =p\left(t, x, x\left(t-\tau_{i}(t)\right), \dot{x}, \dot{x}\left(t-\tau_{i}(t)\right), \ddot{x}, \ddot{x}\left(t-\tau_{i}\right)\right) .
\end{aligned}
$$

Unfortunately, the problem of uniform asymptotic stability, uniform ultimate boundedness, and existence and uniqueness of periodic solutions of the third-order delay differential equation (3), where all the nonlinear terms (specifically, the forcing term $p_{i}$ and the function $f_{i}$ ) are sum of multiple deviating arguments, is yet to be investigated. This is not unconnected with the difficulties associated with the construction of suitable complete Lyapunov functional. The aim of this paper is to fill this gap. We will consider

$$
\begin{aligned}
\dddot{x}+ & \sum_{i=1}^{n} f_{i}\left(t, x, x\left(t-\tau_{i}(t)\right), \dot{x}, \dot{x}\left(t-\tau_{i}(t)\right), \ddot{x},\right. \\
& \left.\ddot{x}\left(t-\tau_{i}(t)\right)\right)+\sum_{i=1}^{n} g_{i}\left(\dot{x}\left(t-\tau_{i}(t)\right)\right) \\
& +\sum_{i=1}^{n} h_{i}\left(x\left(t-\tau_{i}(t)\right)\right)=\sum_{i=1}^{n} p_{i}\left(t, x, x\left(t-\tau_{i}(t)\right), \dot{x},\right. \\
& \left.\dot{x}\left(t-\tau_{i}(t)\right), \ddot{x}, \ddot{x}\left(t-\tau_{i}(t)\right)\right),
\end{aligned}
$$

where $f_{i}, g_{i}, h_{i}$, and $p_{i}$ are continuous functions in their respective arguments on $\mathbb{R}^{+} \times \mathbb{R}^{3 n+3}, \mathbb{R}, \mathbb{R}^{+}$, and $\mathbb{R}^{+} \times \mathbb{R}^{3 n+3}$, respectively, with $\mathbb{R}^{+}=[0, \infty)$ and $\mathbb{R}=(-\infty, \infty)$. The dots indicate differentiation with respect to the independent variable $t$. Equation (3) is equivalent to the system of first-order delay differential equation

$$
\begin{aligned}
\dot{x} & =y \\
\dot{y} & =z \\
\dot{z} & =\sum_{i=1}^{n} p_{i}\left(t, x, x\left(t-\tau_{i}(t)\right), y, y\left(t-\tau_{i}(t)\right), z,\right. \\
& \left.z\left(t-\tau_{i}(t)\right)\right)-\sum_{i=1}^{n} f_{i}\left(t, x, x\left(t-\tau_{i}(t)\right), y,\right. \\
& \left.y\left(t-\tau_{i}(t)\right), z, z\left(t-\tau_{i}(t)\right)\right)-\sum_{i=1}^{n} g_{i}(y(t)) \\
& -\sum_{i=1}^{n} h_{i}(x(t))+\sum_{i=1}^{n} \int_{t-\tau_{i}(t)}^{t} g_{i}(y(s)) z(s) d s \\
& +\sum_{i=1}^{n} \int_{t-\tau_{i}(t)}^{t} h_{i}^{\prime}(x(s)) y(s) d s
\end{aligned}
$$

where $0 \leq \tau_{i}(t) \leq \gamma, \gamma>0$ is a constant to be determined latter, and the derivatives $g_{i}^{\prime}$ and $h_{i}^{\prime}$ for all $i(i=1,2,3, \ldots, n)$ exist and are continuous for all $x$ and $y$ with $h_{i}(0)=0$. This work is motivated by the recent works in $[9,27]$. Our results are new; in fact according to our observation from relevant literature, this is the first paper where both the functions $f_{i}$ and the forcing term $p_{i}$ contain sum of multiple deviating arguments. For the next section, for easy references, we recall the main mathematical tools that will be used in the sequel. Our main results are stated and proved in Section 3 while in the last section, examples are given.

\section{Preliminary Results}

Consider the following general nonlinear nonautonomous delay differential equation

$$
\begin{aligned}
& \dot{X}=\frac{d X}{d t}=F\left(t, X_{t}\right), \\
& \quad X_{t}=X(t+\theta), \quad-r \leq \theta<0, t \geq 0,
\end{aligned}
$$

where $F: \mathbb{R}^{+} \times C_{H} \rightarrow \mathbb{R}^{n}$ is a continuous mapping and $F(t+$ $\omega, \phi)=F(t, \phi)$ for all $\phi \in C$ and for some positive constant $\omega$. We assume that $F$ takes closed bounded sets into bounded sets in $\mathbb{R}^{n}$. $(C,\|\cdot\|)$ is the Banach space of continuous function $\varphi:[-r, 0] \rightarrow \mathbb{R}^{n}$ with supremum norm, $r>0$; for $H>0$, we define $C_{H} \subset C$ by $C_{H}=\{\varphi \in C:\|\varphi\|<H\}$, and $C_{H}$ is the open $H$-ball in $C, C=C\left([-r, 0], \mathbb{R}^{n}\right)$.

Definition 1 (see [2]). A continuous function $W: \mathbb{R}^{+} \rightarrow \mathbb{R}^{+}$ with $W(0)=0, W(s)>0$ if $s \neq 0$ and $W$ strictly increasing is a wedge. (We denote wedges by $W$ or $W_{i}$, where $i$ is an integer.)

Definition 2 (see [2]). The zero solution of (5) is asymptotically stable if it is stable and if for each $t_{0} \geq 0$ there is $\eta>0$ such that $\|\phi\| \leq \eta$ implies that

$$
X\left(t, t_{0}, \phi\right) \longrightarrow 0 \quad \text { as } t \longrightarrow \infty .
$$

Definition 3 (see [1]). An element $\psi \in C_{H}$ is in the $\omega$-limit set of $\phi$, say $\Omega(\phi)$, if $X(t, 0, \phi)$ is defined on $\mathbb{R}^{+}$and there is a sequence $\left\{t_{n}\right\}, t_{n} \rightarrow \infty$ as $n \rightarrow+\infty$, with $\left\|X_{t_{n}}(\phi)-\psi\right\| \rightarrow 0$ as $n \rightarrow \infty$, where $X_{t_{n}}(\phi)=X\left(t_{n}+\theta, 0, \phi\right)$ for $-r \leq \theta<0$.

Definition 4 (see [30]). A set $Q \subset C_{H}$ is an invariant set if, for any $\phi \in Q$, the solution $X(t, 0, \phi)$ of (5) is defined on $\mathbb{R}^{+}$and $X_{t}(\phi) \in Q$ for $t \in \mathbb{R}^{+}$.

Lemma 5 (see [6]). Suppose that $F(t, \phi) \in \bar{C}_{0}(\phi)$ and $F(t, \phi)$ is periodic in tof period $\omega, \omega \geq r$, and consequently for any $\alpha>0$ there exists $L(\alpha)>0$ such that $\phi \in C_{\alpha}$ implies $|F(t, \phi)| \leq L(\alpha)$. Suppose that a continuous Lyapunov functional $V(t, \phi)$ exists, defined on $t \in \mathbb{R}^{+}, \phi \in S^{*}, S^{*}$ is the set of $\phi \in C$ such that $|\phi(0)| \geq H$ (H may be large), and $V(t, \phi)$ satisfies the following conditions:

(i) $a(|\phi(0)|) \leq V(t, \phi) \leq b(\|\phi\|)$, where $a(r)$ and $b(r)$ are continuous, increasing, and positive for $r \geq H$ and $a(r) \rightarrow \infty$ as $r \rightarrow \infty$;

(ii) $\dot{V}_{(5)}(t, \phi) \leq-c(|\phi(0)|)$, where $c(r)$ is continuous and positive for $r \geq H$.

Suppose that there exists $H_{1}>0, H_{1}>H$, such that

$$
h L\left(\gamma^{*}\right)<H_{1}-H,
$$


where $\gamma^{*}>0$ is a constant which is determined in the following way: By the condition on $V(t, \phi)$ there exist $\alpha>0, \beta>0$, and $\gamma>0$ such that $b\left(H_{1}\right) \leq a(\alpha), b(\alpha) \leq a(\beta)$, and $b(\beta) \leq$ $a(\gamma) \cdot \gamma^{*}$ is defined by $b(\gamma) \leq a\left(\gamma^{*}\right)$. Under the above conditions, there exists a periodic solution of (5) of period $\omega$. In particular, relation (7) can always be satisfied if $h$ is sufficiently small.

Lemma 6 (see [6]). Suppose that $F(t, \phi)$ is defined and continuous on $0 \leq t \leq c, \phi \in C_{H}$, and there exists a continuous Lyapunov functional $V(t, \phi, \varphi)$ defined on $0 \leq t \leq c$, $\phi$, and $\varphi \in C_{H}$ which satisfy the following conditions:

(i) $V(t, \phi, \varphi)=0$ if $\phi=\varphi$;

(ii) $V(t, \phi, \varphi)>0$ if $\phi \neq \varphi$;

(iii) for the associated system

$$
\begin{aligned}
& \dot{x}(t)=F\left(t, x_{t}\right), \\
& \dot{y}(t)=F\left(t, y_{t}\right),
\end{aligned}
$$

we have $V_{(8)}^{\prime}(t, \phi, \varphi) \leq 0$, where, for $\|\phi\|=H$ or $\|\varphi\|=$ $H$, we understand that the condition $V_{(8)}^{\prime}(t, \phi, \varphi) \leq 0$ is satisfied in case $V^{\prime}$ can be defined.

Then, for given initial value $\phi \in C_{H_{1}}, H_{1}<H$, there exists a unique solution of (5).

Lemma 7 (see [6]). Suppose that a continuous Lyapunov functional $V(t, \phi)$ exists, defined on $t \in \mathbb{R}^{+},\|\phi\|<H$, and $0<H_{1}<H$ which satisfies the following conditions:

(i) $a(\|\phi\|) \leq V(t, \phi) \leq b(\|\phi\|)$, where $a(r)$ and $b(r)$ are continuous, increasing, and positive;

(ii) $\dot{V}_{(5)}(t, \phi) \leq-c(\|\phi\|)$, where $c(r)$ is continuous and positive for $r \geq 0$;

then the zero solution of (5) is uniformly asymptotically stable.

Lemma 8 (see [1]). Let $V: \mathbb{R}^{+} \times C \rightarrow \mathbb{R}$ be continuous and locally Lipschitz in $\phi$. If

(i) $W_{0}\left(\left|X_{t}\right|\right) \leq V\left(t, X_{t}\right) \leq W_{1}\left(\left|X_{t}\right|\right)+$ $W_{2}\left(\int_{t-r(t)}^{t} W_{3}\left(X_{t}(s)\right) d s\right)$;

(ii) $\dot{V}_{(5)}\left(t, X_{t}\right) \leq-W_{4}\left(\left|X_{t}\right|\right)+N$, for some $N>0$, where $W_{i}(i=0,1,2,3,4)$ are wedges,

then $X_{t}$ of (5) is uniformly bounded and uniformly ultimately bounded for bound $B$.

\section{Main Results}

We will give the following notations before we state our main results. Let

$$
\begin{aligned}
& \sum_{i=1}^{n} f_{i}\left(t, x, x\left(t-\tau_{i}(t)\right), y, y\left(t-\tau_{i}(t)\right), z, z\left(t-\tau_{i}(t)\right)\right) \\
& \quad=\sum_{i=1}^{n} f_{i}(\cdot), \\
& \sum_{i=1}^{n} p_{i}\left(t, x, x\left(t-\tau_{i}(t)\right), y, y\left(t-\tau_{i}(t)\right), z, z\left(t-\tau_{i}(t)\right)\right) \\
& \quad=\sum_{i=1}^{n} p_{i}(\cdot) .
\end{aligned}
$$

For the first case of consideration set $\sum_{i=1}^{n} p_{i}(\cdot) \equiv 0$, system (4) reduces to

$$
\begin{aligned}
\dot{x}= & y, \\
\dot{y}= & z, \\
\dot{z}= & -\sum_{i=1}^{n} f_{i}(\cdot)-\sum_{i=1}^{n} g_{i}(y(t))-\sum_{i=1}^{n} h_{i}(x(t)) \\
& +\sum_{i=1}^{n} \int_{t-\tau_{i}(t)}^{t} g_{i}(y(s)) z(s) d s \\
& +\sum_{i=1}^{n} \int_{t-\tau_{i}(t)}^{t} h_{i}^{\prime}(x(s)) y(s) d s,
\end{aligned}
$$

where $f_{i}, g_{i}, h_{i}$, and $\tau_{i}$ are functions defined in Section 1. Let $\left(x_{t}, y_{t}, z_{t}\right)$ be any solution of (10); the continuously differentiable functional employed in the proof of our results is $V=V\left(t, x_{t}, y_{t}, z_{t}\right)$ defined as

$$
\begin{aligned}
2 V & =2 \sum_{i=1}^{n}\left(\alpha+a_{i}\right) \int_{0}^{x} h_{i}(\xi) d \xi+4 \sum_{i=1}^{n} \int_{0}^{y} g_{i}(\eta) d \eta \\
& +4 y \sum_{i=1}^{n} h_{i}(x)+2 \sum_{i=1}^{n}\left(\alpha+a_{i}\right) y z+2 z^{2}+\sum_{i=1}^{n}\left(\alpha^{2}+\beta\right. \\
& \left.+a_{i}^{2}\right) y^{2}+\sum_{i=1}^{n} \beta b_{i} x^{2}+2 \sum_{i=1}^{n} a_{i} \beta x y+2 \beta x z \\
& +\int_{-\tau_{i}(t)}^{0} \int_{t+s}^{t}\left[\lambda_{1} x^{2}(\theta)+\lambda_{2} y^{2}(\theta)+\lambda_{3} z^{2}(\theta)\right] d \theta d s,
\end{aligned}
$$

where $\alpha$ and $\beta$ are fixed positive constants satisfying

$$
\begin{aligned}
b_{i}^{-1} c_{i} & <\alpha<a_{i} \quad \forall i(i=1,2,3, \ldots, n) ; \\
0 & <\beta \\
& <\min \left\{b_{i}, \sum_{i=1}^{n}\left(\alpha b_{i}-c_{i}\right) A_{1}^{-1}, \sum_{i=1}^{n}\left(a_{i}-\alpha\right) A_{2}^{-1}\right\},
\end{aligned}
$$


with

$$
\begin{aligned}
& A_{1}:=2\left[1+a_{i}+\delta_{i}^{-1}\left(y^{-1} g_{i}(y)-b_{i}\right)^{2}\right], \\
& A_{2}:=4\left[1+\delta_{i}^{-1}\left(z^{-1} f_{i}(\cdot)-a_{i}\right)^{2}\right] .
\end{aligned}
$$

$\lambda_{1}, \lambda_{2}$, and $\lambda_{3}$ are nonnegative constants which will be determined later.

Remark 9. The Lyapunov functional defined in (11) is an improvement on the one used in [9]. proofs.

At last, we now state our main results and give their

Theorem 10. Further to the assumptions on the functions $f_{i}$, $g_{i}, h_{i}$, and $\tau_{i}$, suppose that, for all $i(i=1,2,3, \ldots, n), a_{i}, \delta_{i}, c_{i}$, $B_{i}, \rho$ and $\gamma$ are positive constants and for all $t \geq 0$ :

(i) $f_{i}(\cdot) / z \geq a_{i}$ for all $z \neq 0$;

(ii) $b_{i} \leq g_{i}(y) / y \leq B_{i}$ for all $y \neq 0$;

(iii) $h_{i}(0)=0, h_{i}(x) / x \geq \delta_{i}$ for all $x \neq 0$;

(iv) $h_{i}^{\prime}(x) \leq c_{i}$ for all $x$ and $a_{i} b_{i}-c_{i}>0$;

(v) $\tau_{i}(t) \leq \gamma, \tau_{i}^{\prime}(t) \leq \rho, \rho \in(0,1)$; and if

$$
\begin{gathered}
\gamma<\min \left\{\sum_{i=1}^{n} \delta_{i}\left(B_{i}+c_{i}\right)^{-1}, \sum_{i=1}^{n}\left(a_{i} b_{i}-c_{i}\right) A_{3}^{-1},\right. \\
\left.\sum_{i=1}^{n}\left(a_{i}-\alpha\right) A_{4}^{-1}\right\},
\end{gathered}
$$

where

$$
\begin{aligned}
A_{3}:= & \left(B_{i}+c_{i}\right)\left(\alpha+a_{i}\right) \\
& +c_{i}(1-\rho)^{-1}\left(\alpha+\beta+a_{i}+2\right), \\
A_{4}:= & 22\left(B_{i}+c_{i}\right)+B_{i}(1-\rho)^{-1}\left(\alpha+\beta+a_{i}+2\right) .
\end{aligned}
$$

then the trivial solution of (10) is uniformly asymptotically stable.

Remark 11. (i) If $i=1, f_{1}(\cdot)=\varphi(\dot{x}), g_{1}\left(\dot{x}\left(t-\tau_{1}(t)\right)\right)=g(\dot{x}(t-$ $\tau(t)))$, and $h_{1}\left(x\left(t-\tau_{1}(t)\right)\right)=h(x(t-\tau(t))),(10)$ reduces to the system considered in [29] and some of our hypotheses agree with the hypotheses obtained therein.

(ii) When $i=1$, the functions $f_{1}(\cdot)=g(x, \dot{x}) \ddot{x}, g_{1}(\dot{x}(t-$ $\left.\left.\tau_{1}(t)\right)\right)=f(x(t-\tau), \dot{x}(t-\tau))$, and $h_{1}\left(x\left(t-\tau_{1}(t)\right)\right)=h(x(t-\tau))$ the above result includes that discussed in [24].

(iii) Whenever $i=1, f_{1}(\cdot)=h(\dot{x}) \ddot{x}, g_{1}\left(\dot{x}\left(t-\tau_{1}(t)\right)\right)=$ $g(\dot{x}(t-\tau(t)))$, and $h_{1}\left(x\left(t-\tau_{1}(t)\right)\right)=h(x(t-\tau(t)))$, (10) specializes to that studied in [12]. Thus, the result of Theorem 10 coincides with results in [12] if $i=1$.

(iv) When $\sum_{i=1}^{n} f_{i}(\cdot)=a \ddot{x}, \sum_{i=1}^{n} g_{i}\left(\dot{x}\left(t-\tau_{i}(t)\right)\right)=b \dot{x}$, $\sum_{i=1}^{n} h_{i}\left(x\left(t-\tau_{i}(t)\right)\right)=c x$, and $\sum_{i=1}^{n} p_{i}(\cdot)=0$, (3) reduces to linear constant coefficients differential equations and conditions (i) to (v) of Theorem 10 specialize to the corresponding Routh-Hurwitz criteria $a>0, a b>c$, and $c>0$. (v) When $i=1, f_{1}(\cdot)=a_{1} \ddot{x}, g_{1}\left(\dot{x}\left(t-\tau_{1}(t)\right)\right)=f_{2}(\dot{x}(t-$ $\left.\left.\tau_{1}(t)\right)\right)$, and $h_{i}\left(x\left(t-\tau_{1}(t)\right)\right)=a_{3} x(t)$, (10) specializes to that discussed in [28]. Theorem 10 coincides with the stability result in [28].

(vi) When $\sum_{i=1}^{n} f_{i}(\cdot)=f(\ddot{x}), \sum_{i=1}^{n} g_{i}\left(\dot{x}\left(t-\tau_{i}(t)\right)\right)=g(\dot{x})$, $\sum_{i=1}^{n} h_{i}\left(x\left(t-\tau_{i}(t)\right)\right)=h(x)$, and $\sum_{i=1}^{n} p_{i}(\cdot)=p(t, x, \dot{x}, \ddot{x})$, then (3) reduces to the ordinary differential equation studied in [31].

(vii) If $i=1$ and $\tau_{i}(t)=\tau$ then (3) coincides with (2) discussed in [27]; hence our hypotheses coincide with that of Tunç in [27].

(viii) Whenever $i=1, f_{1}(\cdot)=f(x, \dot{x}) \ddot{x}, g_{1}\left(\dot{x}\left(t-\tau_{1}(t)\right)\right)=$ $g(x(t-\tau(t)), \dot{x}(t-\tau(t)))$, and $h_{1}\left(x\left(t-\tau_{1}(t)\right)\right)=h(x(t-\tau(t)))$, (10) is a particular case of that studied in [7]. Our hypotheses coincide with that in [7] except for $\sup \left\{h^{\prime}(x)\right\}=c>0$ which is replaced by a more general condition.

(ix) Finally, the functions $f_{i}(\cdot)$ and $p_{i}(\cdot)$ used in this paper extend the works in $[7-10,12,24,27-29,31]$.

In what follows, we will state and prove a result that would be useful in the proof of Theorem 10 and subsequent ones.

Lemma 12. Under the hypotheses of Theorem 10 there exist positive constants $D_{0}=D_{0}\left(a_{i}, b_{i}, c_{i}, \delta_{i}, \alpha, \beta\right), D_{1}=D_{1}\left(a_{i}, b_{i}, c_{i}\right.$, $\left.B_{i}, \alpha, \beta\right)$, and $D_{2}=D_{2}\left(\lambda_{1}, \lambda_{2}, \lambda_{3}\right)$ such that for all $\left(x_{t}, y_{t}, z_{t}\right) \in$ $\mathbb{R}^{3}$

$$
\begin{aligned}
& D_{0}\left(x^{2}(t)+y^{2}(t)+z^{2}(t)\right) \leq V\left(t, x_{t}, y_{t}, z_{t}\right) \\
& \leq D_{1}\left(x^{2}(t)+y^{2}(t)+z^{2}(t)\right) \\
& \quad+D_{2} \int_{-\tau_{i}(t)}^{0} \int_{t+s}^{t}\left(x^{2}(\theta)+y^{2}(\theta)+z^{2}(\theta)\right) d \theta d s .
\end{aligned}
$$

Furthermore, there exists a constant $D_{3}=D_{3}\left(a_{i}, b_{i}, c_{i}, B_{i}, \delta_{i}, \alpha\right.$, $\left.\beta, \gamma, \rho, \lambda_{1}, \lambda_{2}, \lambda_{3}\right)>0$ such that

$$
\begin{aligned}
\dot{V}_{(10)} & =\left.\frac{d}{d t} V\left(t, x_{t}, y_{t}, z_{t}\right)\right|_{(10)} \\
& \leq-D_{3}\left(x^{2}(t)+y^{2}(t)+z^{2}(t)\right) .
\end{aligned}
$$

Proof. Let $\left(x_{t}, y_{t}, z_{t}\right)$ be any solution of $(10)$; since $h_{i}(0)=0$, (11) can be recast in the form

$$
\begin{aligned}
V & =\sum_{i=1}^{n} b_{i}^{-1} \int_{0}^{x}\left[\left(\alpha+a_{i}\right) b_{i}-2 h_{i}^{\prime}(\xi)\right] h_{i}(\xi) d \xi \\
& +2 \sum_{i=1}^{n} \int_{0}^{y}\left(\eta^{-1} g_{i}(\eta)-b_{i}\right) \eta d \eta+\sum_{i=1}^{n} b_{i}^{-1}\left(h_{i}(x)\right. \\
& \left.+b_{i} y\right)^{2}+\frac{1}{2} \beta y^{2}+\frac{1}{2} \sum_{i=1}^{n}\left(\beta x+a_{i} y+z\right)^{2}+\frac{1}{2}(\alpha y \\
& +z)^{2}+\frac{1}{2} \sum_{i=1}^{n} \beta\left(b_{i}-\beta\right) x^{2}+\frac{1}{2} \int_{-\tau_{i}(t)}^{0} \int_{t+s}^{t}\left(\lambda_{1} x^{2}(\theta)\right. \\
& \left.+\lambda_{2} y^{2}(\theta)+\lambda_{3} z^{2}(\theta)\right) d \theta d s .
\end{aligned}
$$


From hypotheses (ii), (iii), and (iv) and the fact that the double integrals appearing in inequality (18) are nonnegative, it follows that there exists a constant $K_{0}>0$ such that

$$
V \geq K_{0}\left(x^{2}+y^{2}+z^{2}\right)
$$

for all $x, y$, and $z$, where

$$
\begin{aligned}
K_{0} & =\min \left\{\sum_{i=1}^{n} b_{i}^{-1}\left[\left(\alpha+a_{i}\right) b_{i}-2 c_{i}\right] \delta_{i}\right. \\
& +\sum_{i=1}^{n} b_{i}^{-1} \min \left\{\sum_{i=1}^{n} \delta_{i}, \sum_{i=1}^{n} b_{i}\right\}+\frac{1}{2} \min \left\{\beta, \sum_{i=1}^{n} a_{i}, 1\right\} \\
& +\frac{1}{2} \sum_{i=1}^{n} \beta\left(b_{i}-\beta\right), \sum_{i=1}^{n} b_{i}^{-1} \min \left\{\sum_{i=1}^{n} \delta_{i}, \sum_{i=1}^{n} b_{i}\right\} \\
& +\frac{1}{2} \min \left\{\beta, \sum_{i=1}^{n} a_{i}, 1\right\}+\frac{1}{2} \min \{\alpha, 1\} \\
& \left.+\frac{1}{2} \beta, \frac{1}{2} \min \left\{\beta, \sum_{i=1}^{n} a_{i}, 1\right\}+\frac{1}{2} \min \{\alpha, 1\}\right\} .
\end{aligned}
$$

Estimate (19) establishes the lower inequality in (16) with $K_{0}=D_{0}$, respectively. Moreover, from inequality (19) we find that $V\left(t, x_{t}, y_{t}, z_{t}\right)=0$ if and only if $\left(x^{2}+y^{2}+z^{2}\right)=0$ and $V\left(t, x_{t}, y_{t}, z_{t}\right)>0$ if and only if $\left(x^{2}+y^{2}+z^{2}\right) \neq 0$, and it follows that for all $x, y, z$

$$
V\left(t, x_{t}, y_{t}, z_{t}\right) \longrightarrow+\infty \quad \text { as } x^{2}+y^{2}+z^{2} \longrightarrow \infty .
$$

Furthermore, since $h_{i}(0)=0, h_{i}(x) \leq c_{i} x$ for all $x \neq 0, g_{i}(y) \leq$ $B_{i} y$ for all $y \neq 0$, and inequality $2 x_{1} x_{2} \leq x_{1}^{2}+x_{2}^{2}$, there exists positive constants $K_{1}, K_{2}$ such that

$$
\begin{aligned}
V \leq & K_{1}\left(x^{2}+y^{2}+z^{2}\right) \\
& +K_{2} \int_{-\tau_{i}(t)}^{0} \int_{t+s}^{t}\left[x^{2}(\theta)+y^{2}(\theta)+z^{2}(\theta)\right] d \theta d s,
\end{aligned}
$$

where

$$
\begin{aligned}
K_{1} & =\frac{1}{2} \max \left\{\sum_{i=1}^{n}\left[\left(\alpha+a_{i}+2\right) c_{i}+\beta\left(a_{i}+b_{i}+1\right)\right],\right. \\
& \sum_{i=1}^{n}\left[2\left(B_{i}+c_{i}\right)+a_{i}\left(\alpha+\beta+a_{i}\right)+\alpha^{2}+\beta\right], \\
& \left.\sum_{i=1}^{n}\left[\alpha+\beta+a_{i}+2\right]\right\}, \\
K_{2} & =\max \left\{\lambda_{1}, \lambda_{2}, \lambda_{3}\right\} .
\end{aligned}
$$

Estimate (22) establishes the upper inequality in (16) with $K_{1}=D_{1}$ and $K_{2}=D_{2}$, respectively. Hence, from inequalities (19) and (22) estimate (16) of Lemma 12 is established.
Next, the time derivative of the functional defined in inequality (11) with respect to the independent variable $t$, along a solution of system (10), is simplified to give

$$
\begin{aligned}
& \dot{V}_{(10)}=U_{1}-U_{2}-\beta \sum_{i=1}^{n}\left(\frac{g_{i}(y)}{y}-b_{i}\right) x y \\
& -\beta \sum_{i=1}^{n}\left(\frac{f_{i}(\cdot)}{z}-a_{i}\right) x z+2 \beta y z \\
& -\sum_{i=1}^{n}\left[\left(\alpha+a_{i}\right) \frac{f_{i}(\cdot)}{z}-\left(\alpha^{2}+a_{i}^{2}\right)\right] y z \\
& +\sum_{i=1}^{n} a_{i} \beta y^{2}+\frac{1}{2}\left(\lambda_{1} x^{2}+\lambda_{2} y^{2}+\lambda_{3} z^{2}\right) \tau_{i}(t) \\
& -\frac{1}{2}\left(1-\tau_{i}^{\prime}(t)\right) \\
& \cdot \int_{t+s}^{t}\left(\lambda_{1} x^{2}(s)+\lambda_{2} y^{2}(s)+\lambda_{3} z^{2}(s)\right) d s,
\end{aligned}
$$

where

$$
\begin{aligned}
U_{1} & :=\left(\beta x+\sum_{i=1}^{n}\left(\alpha+a_{i}\right) y+2 z\right) \\
& \cdot \sum_{i=1}^{n} \int_{t-\tau_{i}(t)}^{t}\left(g_{i}^{\prime}(y(s)) z(s)+h_{i}^{\prime}(x(s)) y(s)\right) d s, \\
U_{2} & :=\sum_{i=1}^{n}\left(\beta \frac{h_{i}(x)}{x}\right) x^{2} \\
& +\sum_{i=1}^{n}\left[\left(\alpha+a_{i}\right) \frac{g_{i}(y)}{y}-2 h_{i}^{\prime}(x)\right] y^{2} \\
& +\sum_{i=1}^{n}\left[2 \frac{f_{i}(\cdot)}{z}-\left(\alpha+a_{i}\right)\right] z^{2} .
\end{aligned}
$$

Now from the assumptions of Theorem 10 we find that

$$
\begin{aligned}
U_{1} \leq & \frac{1}{2} \sum_{i=1}^{n}\left(\beta x^{2}+\left(\alpha+a_{i}\right) y^{2}+2 z^{2}\right)\left(B_{i}+c_{i}\right) \tau_{i}(t) \\
& +\frac{1}{2} \sum_{i=1}^{n}\left(\alpha+\beta+a_{i}+2\right) \\
& \cdot \int_{t-\tau_{i}(t)}^{t}\left(c_{i} y^{2}(s)+B_{i} z^{2}(s)\right) d s
\end{aligned}
$$

for all $x, y, z$ and $t \geq 0$ and

$$
\begin{aligned}
U_{2} \geq & \sum_{i=1}^{n} \beta \delta_{i} x^{2}+\sum_{i=1}^{n}\left[\left(\alpha+a_{i}\right) b_{i}-2 c_{i}\right] y^{2} \\
& -\frac{1}{2} \sum_{i=1}^{n}\left(a_{i}-\alpha\right) z^{2}
\end{aligned}
$$


for all $x, y, z$. Using estimates $U_{1}$ and $U_{2}$ in (24), we find that

$$
\begin{aligned}
& \dot{V}_{(10)} \leq-\frac{1}{2} \sum_{i=1}^{n} \beta \delta_{i} x^{2}-\frac{1}{2} \sum_{i=1}^{n}\left[\left(\alpha+a_{i}\right) b_{i}-2 c_{i}\right] y^{2}-\frac{1}{2} \\
& \cdot \sum_{i=1}^{n}\left(a_{i}-\alpha\right) z^{2}-\sum_{j=3}^{4} U_{j}-\frac{1}{2}\left(1-\tau_{i}^{\prime}(t)\right) \\
& \cdot \lambda_{1} \int_{t-\tau_{i}(t)}^{t} x^{2}(s) d s+\frac{1}{2}\left[\sum_{i=1}^{n} \beta\left(B_{i}+c_{i}\right)+\lambda_{1}\right] \tau_{i}(t) \\
& \cdot x^{2}-\frac{1}{2}\left[\left(1-\tau_{i}^{\prime}(t)\right) \lambda_{2}-\sum_{i=1}^{n}\left(\alpha+\beta+a_{i}+2\right) c_{i}\right] \\
& \cdot \int_{t-\tau_{i}(t)}^{t} y^{2}(s) d s+\beta z^{2} \\
& -\frac{1}{2}\left[\left(1-\tau_{i}^{\prime}(t)\right) \lambda_{3}-\sum_{i=1}^{n}\left(\alpha+\beta+a_{i}+2\right) B_{i}\right] \\
& \cdot \int_{t-\tau_{i}(t)}^{t} z^{2}(s) d s+\sum_{i=1}^{n} \beta\left(a_{i}+1\right) y^{2} \\
& +\frac{1}{2}\left[\sum_{i=1}^{n}\left(B_{i}+c_{i}\right)\left(\alpha+a_{i}\right)+\lambda_{2}\right] \tau_{i}(t) y^{2} \\
& +\frac{1}{2}\left[2 \sum_{i=1}^{n}\left(B_{i}+c_{i}\right)+\lambda_{3}\right] \tau_{i}(t) z^{2}
\end{aligned}
$$

for all $x, y, z$, where

$$
\begin{aligned}
U_{3} & :=\frac{1}{4} \sum_{i=1}^{n} \beta \delta_{i} x^{2}+\beta \sum_{i=1}^{n}\left(y^{-1} g_{i}(y)-b_{i}\right) x y+\frac{1}{4} \\
& \cdot \sum_{i=1}^{n} \beta \delta_{i} x^{2}+\beta \sum_{i=1}^{n}\left(z^{-1} f_{i}(\cdot)-a_{i}\right) x z, \\
U_{4} & :=\frac{1}{2}\left[\sum_{i=1}^{n}\left[\left(\alpha+a_{i}\right) b_{i}-2 c_{i}\right] y^{2}\right. \\
& +2 \sum_{i=1}^{n}\left[\left(\alpha+a_{i}\right) z^{-1} f_{i}(\cdot)-\left(\alpha^{2}+a_{i}^{2}\right)\right] y z \\
& \left.+\sum_{i=1}^{n}\left(a_{i}-\alpha\right) z^{2}\right] .
\end{aligned}
$$

Since $\beta>0, \delta_{i}>0$, and

$$
\begin{gathered}
\sum_{i=1}^{n}\left[x+2 \delta_{i}^{-1}\left(y^{-1} g_{i}(y)-b_{i}\right) y\right]^{2} \geq 0, \\
\sum_{i=1}^{n}\left[x+2 \delta_{i}^{-1}\left(z^{-1} f_{i}(\cdot)-a_{i}\right) z\right]^{2} \geq 0
\end{gathered}
$$

for all $x, y, z$, we find

$$
\begin{aligned}
U_{3} \geq & -\beta \sum_{i=1}^{n} \delta_{i}^{-1}\left(y^{-1} g_{i}(y)-b_{i}\right)^{2} y^{2} \\
& -\beta \sum_{i=1}^{n} \delta_{i}^{-1}\left(z^{-1} f_{i}(\cdot)-a_{i}\right)^{2} z^{2}
\end{aligned}
$$

for all $y$ and $z$. Moreover, using the estimate

$$
\begin{gathered}
\sum_{i=1}^{n}\left[\left(\alpha+a_{i}\right) z^{-1} f_{i}(\cdot)-\left(\alpha^{2}+a_{i}^{2}\right)\right]^{2} \\
<\sum_{i=1}^{n}\left[\left(\alpha+a_{i}\right) b_{i}-2 c_{i}\right]\left(a_{i}-\alpha\right)
\end{gathered}
$$

in $U_{4}$ we obtain

$$
\begin{aligned}
U_{4} & \geq \frac{1}{2}\left[\sqrt{\sum_{i=1}^{n}\left[\left(\alpha+a_{i}\right) b_{i}-2 c_{i}\right]}|y|\right. \\
& \left.-\sqrt{\sum_{i=1}^{n}\left(a_{i}-\alpha\right)|z|}\right]^{2} \geq 0
\end{aligned}
$$

for all $y$ and $z$. Inserting estimates $U_{3}$ and $U_{4}$ in inequality (28) with hypothesis $(v)$ of Theorem 10, choosing $\lambda_{1}=0, \lambda_{2}=$ $\sum_{i=1}^{n}(1-\rho)^{-1}\left(\alpha+\beta+a_{i}+2\right) c_{i}>0$, and $\lambda_{3}=\sum_{i=1}^{n}(1-\rho)^{-1}(\alpha+$ $\left.\beta+a_{i}+2\right) B_{i}>0$, we have

$$
\begin{aligned}
& \dot{V}_{(10)} \leq-\frac{1}{2} \sum_{i=1}^{n}\left[a_{i} b_{i}-c_{i}-\left[\left(B_{i}+c_{i}\right)\left(\alpha+a_{i}\right)\right.\right. \\
& \left.\left.+c_{i}(1-\rho)^{-1}\left(\alpha+\beta+a_{i}+2\right)\right] \gamma\right] y^{2}-\frac{1}{4} \sum_{i=1}^{n}\left[\left(a_{i}\right.\right. \\
& -\alpha)-2\left[2\left(B_{i}+c_{i}\right)\right. \\
& \left.\left.+B_{i}(1-\rho)^{-1}\left(\alpha+\beta+a_{i}+2\right)\right] \gamma\right] z^{2}-\left\{\frac { 1 } { 2 } \sum _ { i = 1 } ^ { n } \left(\alpha b_{i}\right.\right. \\
& \left.\left.\quad-c_{i}\right)-\beta \sum_{i=1}^{n}\left[1+a_{i}+\delta_{i}^{-1}\left(y^{-1} g_{i}(y)-b_{i}\right)^{2}\right]\right\} y^{2} \\
& \quad-\left\{\frac{1}{4} \sum_{i=1}^{n}\left(a_{i}-\alpha\right)-\beta \sum_{i=1}^{n}[1\right. \\
& \left.\left.+\delta_{i}^{-1}\left(z^{-1} f_{i}(\cdot)-a_{i}\right)^{2}\right]\right\} z^{2}-\frac{1}{2} \sum_{i=1}^{n} \beta\left[\delta_{i}-\left(B_{i}+c_{i}\right)\right. \\
& \cdot \gamma] x^{2}
\end{aligned}
$$

for all $x, y, z$.

Now in view of the inequalities in (12) there exists a positive constant $K_{3}$ such that

$$
\dot{V}_{(10)} \leq-K_{3}\left(x^{2}+y^{2}+z^{2}\right) \quad \forall(x, y, z) \in \mathbb{R}^{3},
$$

where

$$
\begin{aligned}
K_{3} & =\min \left\{\frac{1}{2} \sum_{i=1}^{n} \beta\left[\delta_{i}-\left(B_{i}+c_{i}\right) \gamma\right], \frac{1}{2} \sum_{i=1}^{n}\left[a_{i} b_{i}-c_{i}\right.\right. \\
- & {\left[\left(B_{i}+c_{i}\right)\left(\alpha+a_{i}\right)+c_{i}(1-\rho)^{-1}\left(\alpha+\beta+a_{i}+2\right)\right] } \\
\cdot & \gamma], \frac{1}{4} \sum_{i=1}^{n}\left[\left(a_{i}-\alpha\right)\right. \\
& \left.\left.-2\left[2\left(B_{i}+c_{i}\right)+B_{i}(1-\rho)^{-1}\left(\alpha+\beta+a_{i}+2\right)\right] \gamma\right]\right\} .
\end{aligned}
$$


Inequality (35) establishes (17) with $K_{3}=D_{3}$, respectively. This completes the proof of Lemma 12.

Proof of Theorem 10. Let $\left(x_{t}, y_{t}, z_{t}\right)$ be any solution of system (10), in view of the inequalities in (19), (22), and (35); all the assumptions of Lemma 7 hold. Thus by Lemma 7 the trivial solution of system (10) or (3) for $p_{i}(\cdot)=0$ is uniformly asymptotically stable. This completes the proof of Theorem 10 .

Next, we will consider the case of $p_{i}(\cdot) \neq 0$, and we have the following result.

Theorem 13. If hypotheses (i)-(v) and the inequality in (14) of Theorem 10 hold and

$$
\left|p_{i}(\cdot)\right| \leq \phi_{i}(t)+\varphi_{i}(t)(|x|+|y|+|z|)
$$

for all $i(i=1,2, \ldots, n),(x, y, z) \in \mathbb{R}^{3}$, and $t \geq 0$, where $\phi_{i}(t)$ and $\varphi_{i}(t)$ are continuous functions satisfying

$$
\phi_{i}(t) \leq d_{i}, \quad 0<d_{i}<\infty
$$

and there exists an $\epsilon_{i}>0$ such that

$$
0 \leq \varphi_{i}(t) \leq \epsilon_{i}
$$

then

(i) the solutions of system (4) are uniformly bounded and uniformly ultimately bounded;

(ii) equation (4) has a unique periodic solution of period $\omega$.

Remark 14. (i) Whenever $i=1, f_{1}(\cdot)=f(x, \dot{x}) \ddot{x}, g_{1}(\dot{x}(t-$ $\left.\left.\tau_{1}(t)\right)\right)=g(x(t-\tau(t)), \dot{x}(t-\tau(t))), h_{1}\left(x\left(t-\tau_{1}(t)\right)\right)=h(x(t-$ $\tau(t)))$, and $p_{1}(\cdot)=p(t, x, \dot{x}, \ddot{x}, x(t-\tau(t)), \dot{x}(t-\tau(t)))$, system (4) is a particular case of that studied in [7]. Our hypotheses coincide with that in [7] except for $\sup \left\{h^{\prime}(x)\right\}=c>0$ which is replaced by a more general condition in ours.

(ii) If $i=1, f_{1}(\cdot)=\varphi(x, \dot{x}) \ddot{x}, g_{1}\left(\dot{x}\left(t-\tau_{1}(t)\right)\right)=g(\dot{x}(t-$ $\tau(t))), h_{1}\left(x\left(t-\tau_{1}(t)\right)\right)=f(x(t-\tau(t)))$, and $p_{1}(\cdot)=p(t, x$, $\dot{x}, \ddot{x})$, system (4) reduces to that considered in [16].

(iii) When $i=1$, the functions $f_{1}(\cdot)=g(x, \dot{x}) \ddot{x}, g_{1}(\dot{x}(t-$ $\left.\left.\tau_{1}(t)\right)\right)=f(x(t-\tau), \dot{x}(t-\tau)), h_{1}\left(x\left(t-\tau_{1}(t)\right)\right)=h(x(t-\tau))$, and $p_{1}(\cdot)=p(t, x, \dot{x}, x(t-\tau), \dot{x}(t-\tau), \ddot{x})$, the above result includes that discussed in [24].

(iv) Whenever $i=1, f_{1}(\cdot)=h(\dot{x}) \ddot{x}, g_{1}\left(\dot{x}\left(t-\tau_{1}(t)\right)\right)=$ $g(\dot{x}(t-\tau(t))), h_{1}\left(x\left(t-\tau_{1}(t)\right)\right)=h(x(t-\tau(t)))$, and $p_{1}(\cdot)=p(t$, $x, \dot{x}, x(t-\tau), \dot{x}(t-\tau), \ddot{x}),(4)$ specializes to that studied in [12].

(v) When $i=1, f_{1}(\cdot)=a_{1} \ddot{x}, g_{1}\left(\dot{x}\left(t-\tau_{1}(t)\right)\right)=f_{2}(\dot{x}(t-$ $\left.\left.\tau_{1}(t)\right)\right), h_{i}\left(x\left(t-\tau_{1}(t)\right)\right)=a_{3} x(t), p_{1}(\cdot)=p\left(t, x, \dot{x}, x\left(t-\tau_{1}(t)\right)\right.$, $\left.\dot{x}\left(t-\tau_{1}(t)\right), \ddot{x}\right)$, and $\varphi_{i}(t)=0$, system (4) reduces to that considered in [28]. Theorem 13 coincides with the boundedness result in [28]. (vi) If $i=1$, and $\varphi_{i}(t) \equiv 0$ in inequality (37), our result specializes to that studied in $[9,27]$.

(vii) Whenever $i=1$, in inequality (37) the result in Theorem 13 reduces to that discussed in [8].

Hence, Theorem 13 includes and improves the results in $[7-9,12,16,24,27,28]$.

Proof of Theorem 13. (i) Let $\left(x_{t}, y_{t}, z_{t}\right)$ be any solution of system (4); the time derivative of the functional $V \equiv V\left(t, x_{t}\right.$, $y_{t}, z_{t}$ ) defined in system (11) along a solution of system (4) is

$$
\dot{V}_{(4)}=\dot{V}_{(10)}+\sum_{i=1}^{n}\left[\beta x+\left(\alpha+a_{i}\right) y+2 z\right] p_{i}(\cdot) .
$$

Using inequality (35), the above relation becomes

$$
\begin{aligned}
\dot{V}_{(4)} \leq & -K_{3}\left(x^{2}+y^{2}+z^{2}\right) \\
& +K_{4}(|x|+|y|+|z|) \sum_{i=1}^{n}\left|p_{i}(\cdot)\right|
\end{aligned}
$$

where $K_{4}=\max \left\{\beta, \sum_{i=1}^{n}\left(\alpha+a_{i}\right), 2\right\}$. Applying inequality (37), we find that

$$
\begin{aligned}
\dot{V}_{(4)} \leq & -K_{3}\left(x^{2}+y^{2}+z^{2}\right) \\
& +K_{4}(|x|+|y|+|z|) \sum_{i=1}^{n} \phi_{i}(t) \\
& +K_{4}(|x|+|y|+|z|)^{2} \sum_{i=1}^{n} \varphi_{i}(t) .
\end{aligned}
$$

From estimates (38) and (39) and on choosing $K_{3}>$ $K_{4} \sum_{i=1}^{n}\left(d_{i}+\epsilon_{i}\right)$, there exist constants $K_{5}>0$ and $K_{6}>0$ such that

$$
\dot{V}_{(4)} \leq-K_{5}\left(x^{2}+y^{2}+z^{2}\right)+K_{6}, \quad \forall(x, y, z) \in \mathbb{R}^{3}
$$

where $K_{5}:=K_{3}-K_{4} \sum_{i=1}^{n}\left(d_{i}+\epsilon_{i}\right)$ and $K_{6}:=3 K_{4} \sum_{i=1}^{n} d_{i}$.

The inequalities in (19), (22), and (43) establish the hypotheses of Lemma 8 . Hence by Lemma 8, the solution $\left(x_{t}, y_{t}, z_{t}\right)$ of system (4) is uniformly bounded and uniformly ultimately bounded.

(ii) From estimate (42), using the inequalities in (38) and (39), we have

$$
\begin{aligned}
\dot{V}_{(4)} \leq & -\left(K_{3}-3 K_{4} \sum_{i=1}^{n} \epsilon_{i}\right)\left(x^{2}+y^{2}+z^{2}\right) \\
& +3^{1 / 2} K_{4} \sum_{i=1}^{n} d_{i}\left(x^{2}+y^{2}+z^{2}\right)^{1 / 2} .
\end{aligned}
$$

Choosing $\epsilon_{i}(i=1,2, \ldots, n)$ sufficiently small such that $K_{7}:=$ $K_{3}-3 K_{4} \sum_{i=1}^{n} \epsilon_{i}>0$ and $K_{8}:=3^{1 / 2} K_{4} \sum_{i=1}^{n} d_{i}$ we have

$$
\dot{V}_{(4)} \leq-K_{9}\left(x^{2}+y^{2}+z^{2}\right) \quad \forall(x, y, z) \in \mathbb{R}^{3},
$$


provided that $\left(x^{2}+y^{2}+z^{2}\right)^{1 / 2} \geq K_{10}:=2 K_{8} K_{7}^{-1}>0$ where $K_{9}:=(1 / 2) K_{7}>0$. In view of (19), (21), (22), and (45) all assumptions of Lemmas 5 and 6 are met. Hence by Lemmas 5 and 6 , system (4) has a unique periodic solution of period $\omega$. This completes the proof of Theorem 13.

Next, if $p_{i}(\cdot)$ in system $(4)$ is replaced by $p_{i}(t) \neq 0$, we have

$$
\begin{aligned}
\dot{x}= & y, \\
\dot{y}= & z, \\
\dot{z}= & \sum_{i=1}^{n} p_{i}(t)-\sum_{i=1}^{n} f_{i}(\cdot)-\sum_{i=1}^{n} g_{i}(y)-\sum_{i=1}^{n} h_{i}(x) \\
& +\sum_{i=1}^{n} \int_{t-\tau_{i}(t)}^{t} g_{i}^{\prime}(y(s)) z(s) d s \\
& +\sum_{i=1}^{n} \int_{t-\tau_{i}(t)}^{t} h_{i}^{\prime}(x(s)) y(s) d s,
\end{aligned}
$$

where $f_{i}, g_{i}$, and $h_{i}$ are the functions defined in Section 1 , and $p_{i}: \mathbb{R}^{+} \rightarrow \mathbb{R}$, we have the following result.

Theorem 15. If hypotheses (i)-(v) and estimate (14) of Theorem 10 hold, and

$$
\int_{0}^{t}\left|p_{i}(s)\right| d s \leq q_{i}, \quad 0 \leq q_{i}<\infty, \quad(i=1,2, \ldots, n),
$$

then for any given finite constants $x_{0}, y_{0}, z_{0}$ there exists a constant $D_{4}=D_{4}\left(x_{0}, y_{0}, z_{0}, \alpha, \beta, a_{i}, b_{i}, c_{i}, \delta_{i}\right)$ such that any solution $\left(x_{t}, y_{t}, z_{t}\right)$ of system (46) determined by $x_{0}=x_{0}, y_{0}=y_{0}$, $z_{0}=z_{0}$, for $t=0$, satisfies

$$
\begin{aligned}
& \left|x_{t}\right| \leq D_{4}, \\
& \left|y_{t}\right| \leq D_{4}, \\
& \left|z_{t}\right| \leq D_{4}
\end{aligned}
$$

for all $t>0$.

Remark 16. if $i=1, f_{1}(\cdot)=f_{1}(t, x) \ddot{x}, g_{1}\left(\dot{x}\left(t-\tau_{1}(t)\right)\right)=f_{2}(t$, $x) \dot{x}+g_{0}(t, x), h_{i}\left(x\left(t-\tau_{1}(t)\right)\right)=g_{i}(x(t-\tau(t)))$, and $p_{1}(\cdot)=p(t)$, (46) reduces to that considered in [19]. Our results are quite different from this because of the non-Liapunov approach used in [19].

Proof of Theorem 15. Let $\left(x_{t}, y_{t}, z_{t}\right)$ be any solution of system (46). In view of the hypotheses (i) $-(\mathrm{v})$ and estimate (14), inequality (19) holds. The derivative of the functional $V$ defined in system (11) with respect to the independent variable $t$ along a solution of system (46) is

$$
\dot{V}_{(48)}=\dot{V}_{(10)}+\sum_{i=1}^{n}\left[\beta x+\left(\alpha+a_{i}\right) y+2 z\right] p_{i}(t) .
$$

By inequality (35), $\dot{V}_{(10)} \leq 0$ for all $(x, y, z) \in \mathbb{R}^{3}$, and from the fact that $\left|x_{1}\right| \leq 1+x_{1}^{2}$, it follows that

$$
\dot{V}_{(48)} \leq 3 K_{4} \sum_{i=1}^{n}\left|p_{i}(t)\right|+K_{4}\left(x^{2}+y^{2}+z^{2}\right) \sum_{i=1}^{n}\left|p_{i}(t)\right|,
$$

for all $x, y, z$ and $t \geq 0$. Also from inequality (19), the above inequality becomes

$$
\dot{V}_{(48)}-K_{0}^{-1} K_{4} V \sum_{i=1}^{n}\left|p_{i}(t)\right| \leq 3 K_{4} \sum_{i=1}^{n}\left|p_{i}(t)\right| .
$$

Solving this first-order differential inequality by multiplying each side by

$$
\exp \left[-K_{0}^{-1} K_{4} \sum_{i=1}^{n} \int_{0}^{t}\left|p_{i}(s)\right| d s\right]
$$

integrating from 0 to $t$, and employing inequality (47), we find that

$$
V=V\left(t, x_{t}, y_{t}, z_{t}\right) \leq[V(0)+1] e^{K_{0}^{-1} K_{4} \sum_{i=1}^{n} q_{i}}-1,
$$

where $V(0)=V\left(0, x_{0}, y_{0}, z_{0}\right)$.

Engaging inequality (19), we have

$$
\begin{aligned}
& \left|x_{t}\right| \leq K_{11}, \\
& \left|y_{t}\right| \leq K_{11}, \\
& \left|z_{t}\right| \leq K_{11}
\end{aligned}
$$

for all $t>0$, where

$$
K_{11}:=\left\{\left[[V(0)+1] e^{K_{0}^{-1} K_{4} \sum_{i=1}^{n} q_{i}}-1\right] K_{0}^{-1}\right\}^{1 / 2} .
$$

Equating $K_{11}=D_{4}$, the inequalities in (48) are satisfied. This completes the proof of Theorem 15.

\section{Examples}

Example 1. Consider the homogeneous third-order scalar delay differential equation

$$
\begin{aligned}
\dddot{x} & +\sum_{i=1}^{n}\left[3 \ddot{x}+\frac{\ddot{x}}{5+\sin t+\left|x\left(t-\tau_{i}(t)\right) \dot{x}\left(t-\tau_{i}(t)\right)\right|+\left|\dot{x}\left(t-\tau_{i}(t)\right) \ddot{x}\left(t-\tau_{i}(t)\right)\right|}\right] \\
& +\sum_{i=1}^{n}\left[3 \dot{x}\left(t-\tau_{i}(t)\right)+\frac{\dot{x}\left(t-\tau_{i}(t)\right)}{4+\sin 2 t+\left|x\left(t-\tau_{i}(t)\right)\right|+\left|\dot{x}\left(t-\tau_{i}(t)\right)\right|}\right]+\sum_{i=1}^{n}\left[3 x\left(t-\tau_{i}(t)\right)+\frac{x\left(t-\tau_{i}(t)\right)}{3+\sin 2 t}\right]=0 .
\end{aligned}
$$


Reducing (56) to system of first-order delay differential equations by setting $\dot{x}=y$ and $\ddot{x}=z$ we obtain

$$
\begin{aligned}
\dot{x} & =y \\
\dot{y} & =z \\
\dot{z} & =\sum_{i=1}^{n} \int_{t-\tau_{i}(t)}^{t}\left[3+\frac{4+\sin \mu+|x|}{[4+\sin \mu+|x|+|y|]^{2}}\right] d \mu+\sum_{i=1}^{n} \int_{t-\tau_{i}(t)}^{t}\left[3+\frac{1}{[3+\sin 2 \mu]^{2}}\right] d \mu-\left[3 x+\frac{x}{3+\sin 2 t}\right] \\
& -\left[3 y+\frac{y}{4+\sin t+|x|+|y|}\right]-\sum_{i=1}^{n}\left[3 z+\frac{z}{5+\sin t+\left|x\left(t-\tau_{i}(t)\right) y\left(t-\tau_{i}(t)\right)\right|+\left|y\left(t-\tau_{i}(t)\right) z\left(t-\tau_{i}(t)\right)\right|}\right] .
\end{aligned}
$$

Comparing system (10) with system (57), we have the following relations:

(1) The function $\sum_{i=1}^{n} f_{i}(\cdot)=3 z+z /(5+\sin t+\mid x(t-$ $\left.\left.\tau_{i}(t)\right) y\left(t-\tau_{i}(t)\right)|+| y\left(t-\tau_{i}(t)\right) z\left(t-\tau_{i}(t)\right) \mid\right)$. It is clear from the above equation that

$$
0<3=\sum_{i=1}^{n} a_{i} \leq \sum_{i=1}^{n} \frac{f_{i}(\cdot)}{z}, \quad z \neq 0 .
$$

(2) The function $\sum_{i=1}^{n} g_{i}(y)=3 y+y /(4+\sin t+|x|+|y|)$. It is not difficult to show that

$$
3=\sum_{i=1}^{n} b_{i} \leq \sum_{i=1}^{n} \frac{g_{i}(y)}{y} \leq \sum_{i=1}^{n} B_{i}=4, \quad y \neq 0 .
$$

(3) The function $\sum_{i=1}^{n} h_{i}(x)=3 x+x /(3+\sin 2 t)$, from where we obtain the following estimates:

(a) $3=\sum_{i=1}^{n} \delta_{i} \leq \sum_{i=1}^{n} h_{i}(x) / x, x \neq 0$;

(b) $\sum_{i=1}^{n} h_{i}^{\prime}(x) \leq \sum_{i=1}^{n} c_{i}, \sum_{i=1}^{n}\left(a_{i} b_{i}-c_{i}\right)=5>0$.

(4) The calculation of the following constants also follows:
(a) $4 / 3<\alpha<3$; we choose $\alpha=2$;
(b) $0<\beta<\min \{4,1 / 4,1 / 4\}=1 / 4$ or $0<\beta<1 / 4$, and we choose $\beta=1 / 8$;
(c) $0<\rho<1$, and we choose $\rho=1 / 2$;
(d) $\gamma<\min \{3 / 8,1 / 21,1 / 146\}=1 / 146$.

All the assumptions of Theorem 10 are satisfied. Hence by Theorem 10 trivial solution of system (57) is uniformly asymptotically stable.

Example 2. Consider the nonhomogeneous third-order delay differential equation:

$$
\begin{aligned}
\dddot{x} & +\sum_{i=1}^{n}\left[3 \ddot{x}+\frac{\dot{x}}{5+\sin t+\left|x\left(t-\tau_{i}(t)\right) \dot{x}\left(t-\tau_{i}(t)\right)\right|+\left|\dot{x}\left(t-\tau_{i}(t)\right) \ddot{x}\left(t-\tau_{i}(t)\right)\right|}\right] \\
& +\sum_{i=1}^{n}\left[3 \dot{x}\left(t-\tau_{i}(t)\right)+\frac{\dot{x}\left(t-\tau_{i}(t)\right)}{4+\sin 2 t+\left|x\left(t-\tau_{i}(t)\right)\right|+\left|\dot{x}\left(t-\tau_{i}(\mathrm{t})\right)\right|}\right] \\
& +\sum_{i=1}^{n}\left[3 x\left(t-\tau_{i}(t)\right)+\frac{x\left(t-\tau_{i}(t)\right)}{3+\sin 2 t}\right]=\sum_{i=1}^{n}\left[\frac{1+\cos 2 t+M(t) N_{i}(*)}{(1+\sin 2 t+\cos 2 t+\cos 2 t \sin 2 t) N_{i}(*)}\right],
\end{aligned}
$$

where

$$
+\ddot{x}\left(t-\tau_{i}(t)\right)
$$

$M(t):=2+2 \sin 2 t+\cos 2 t+\cos 2 t \sin 2 t$,

$N_{i}(*):=1+x+\dot{x}+\ddot{x}+x\left(t-\tau_{i}(t)\right)+\dot{x}\left(t-\tau_{i}(t)\right)$

As usual, system (60) is equivalent to 


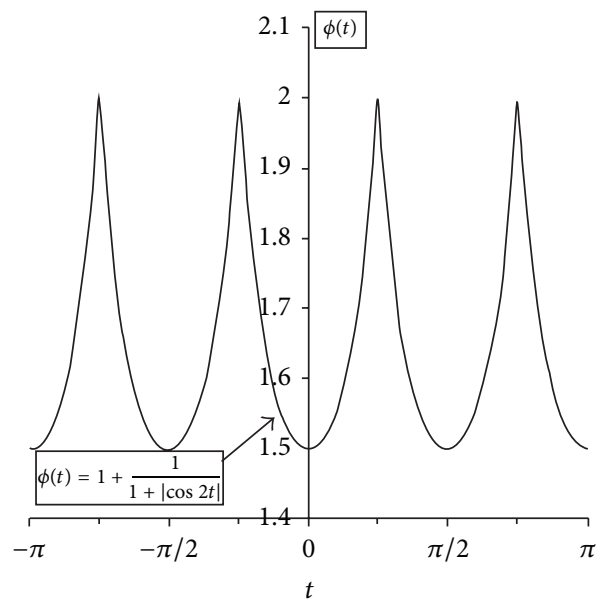

FIgURE 1: Periodic function $\phi(t)=\phi_{i}(t)$.

$$
\begin{aligned}
\dot{x}= & y \\
\dot{y}= & z \\
\dot{z}= & \sum_{i=1}^{n} \int_{t-\tau_{i}(t)}^{t}\left[3+\frac{4+\sin \mu+|x|}{[4+\sin \mu+|x|+|y|]^{2}}\right] d \mu+\sum_{i=1}^{n} \int_{t-\tau_{i}(t)}^{t}\left[3+\frac{1}{[3+\sin 2 \mu]^{2}}\right] d \mu-\left[3 x+\frac{x}{3+\sin 2 t}\right] \\
& -\left[3 y+\frac{y}{4+\sin t+|x|+|y|}\right]-\sum_{i=1}^{n}\left[3 z+\frac{z}{5+\sin t+\left|x\left(t-\tau_{i}(t)\right) y\left(t-\tau_{i}(t)\right)\right|+\left|y\left(t-\tau_{i}(t)\right) z\left(t-\tau_{i}(t)\right)\right|}\right] \\
& +\sum_{i=1}^{n}\left[\frac{1+\cos 2 t+M(t) Q_{i}(*)}{(1+\sin 2 t+\cos 2 t+\cos 2 t \sin 2 t) Q_{i}(*)}\right]
\end{aligned}
$$

where

Comparing systems (4) and (62) we observe that the function

$$
\begin{aligned}
& \sum_{i=1}^{n} p_{i}(\cdot) \\
& \quad=\sum_{i=1}^{n}\left[\frac{1+\cos 2 t+M(t) Q_{i}(*)}{(1+\sin 2 t+\cos 2 t+\cos 2 t \sin 2 t) Q_{i}(*)}\right] .
\end{aligned}
$$

$$
\begin{aligned}
Q_{i}(*):= & +x+y+z+x\left(t-\tau_{i}(t)\right)+y\left(t-\tau_{i}(t)\right) \\
& +z\left(t-\tau_{i}(t)\right) .
\end{aligned}
$$

Substituting appropriately for $Q_{i}(*)$ and $M(t)$, the above equation can be recast in the form

$$
\sum_{i=1}^{n} p_{i}(\cdot)=\sum_{i=1}^{n}\left[1+\frac{1}{1+\cos 2 t}+\frac{1}{(1+\sin 2 t)\left(1+x+y+z+x\left(t-\tau_{i}(t)\right)+y\left(t-\tau_{i}(t)\right)+z\left(t-\tau_{i}(t)\right)\right)}\right]
$$

or

$$
\begin{aligned}
& \sum_{i=1}^{n}\left|p_{i}(\cdot)\right| \leq \sum_{i=1}^{n}\left[1+\frac{1}{1+|\cos 2 t|}\right. \\
& \left.\quad+\frac{1}{(1+|\sin 2 t|)(1+|x|+|y|+|z|)}\right]
\end{aligned}
$$

From inequalities (37) and (66) we obtain the following periodic functions (see Figures 1 and 2):

$$
\begin{aligned}
& \sum_{i=1}^{n} \phi_{i}(t)=1+\frac{1}{1+|\cos 2 t|}, \\
& \sum_{i=1}^{n} \varphi_{i}(t)=\frac{1}{1+|\sin 2 t|} .
\end{aligned}
$$




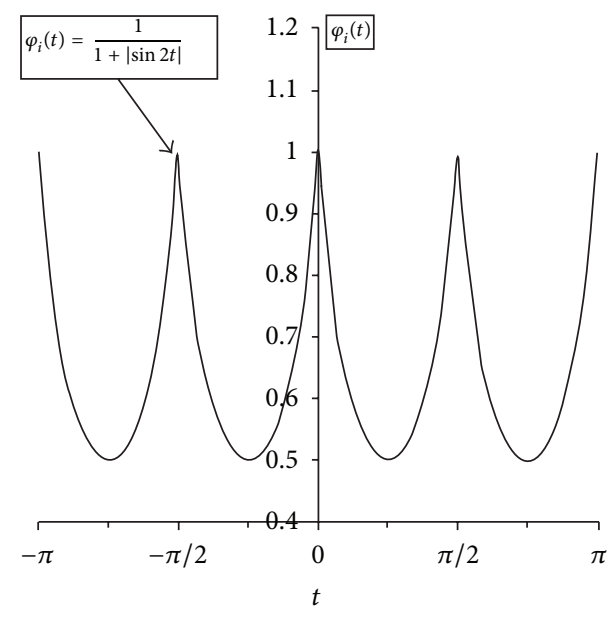

FIgURE 2: Periodic function $\varphi(t)=\varphi_{i}(t)$.

It is not difficult to show that

$$
\begin{aligned}
& 0 \leq \sum_{i=1}^{n} \phi_{i}(t) \leq \sum_{i=1}^{\mathrm{n}} d_{i}=2, \\
& 0 \leq \sum_{i=1}^{n} \varphi_{i}(t) \leq \sum_{i=1}^{n} \epsilon_{i}=1 .
\end{aligned}
$$

The estimates in (68) and that of Example 1 satisfy the hypotheses of Theorem 13. Hence by Theorem 13,

(i) solutions of system (62) are uniformly bounded and uniformly ultimately bounded;

(ii) system (62) has a unique periodic solution of period $\omega=\pi / 2$.

\section{Conflict of Interests}

The authors declare that there is no conflict of interests regarding the publication of this paper.

\section{References}

[1] T. A. Burton, "Stability and periodic solutions of ordinary and functional differential equations," in Mathematics in Science and Engineering, vol. 178, Academic Press, Orlando, Fla, USA, 1985.

[2] T. A. Burton, Volterra Integral and Differential Equations, Academic Press, New York, NY, USA, 1983.

[3] R. D. Driver, Ordinary and Delay Differential Equations, Springer, New York, NY, USA, 1976.

[4] J. K. Hale, Theory of Functional Differential Equations, Springer, New York, NY, USA, 1977.

[5] T. Yoshizawa, Stability Theory by Liapunov's Second Method, The Mathematical Society of Japan, 1966.

[6] T. Yoshizawa, Stability Theory and Existence of Periodic Solutions and Almost Periodic Solutions, Springer, Berlin, Germany, 1975.

[7] A. M. A. Abou-El-Ela, A. I. Sadek, and A. M. Mahmoud, "Stability and boundedness of solutions of certain third order non linear delay differential equation," ICGST-ACSE Journal, vol. 9, no. 1, pp. 9-15, 2009.
[8] A. T. Ademola and P. O. Arawomo, "Uniform stability and boundedness of solutions of nonlinear delay differential equations of the third order," Mathematical Journal of Okayama University, vol. 55, pp. 157-166, 2013.

[9] A. T. Ademola, "Existence and uniqueness of a periodic solution to certain third order nonlinear delay differential equation with multiple deviating arguments," Acta Universitatis Sapientiae, Mathematica, vol. 5, no. 2, pp. 113-131, 2013.

[10] A. T. Ademola, P. O. Arawomo, M. O. Ogunlaran, and E. A. Oyekan, "Uniform stability, boundedness and asymptotic behaviour of solutions of some third order nonlinear delay differential equations," Differential Equations and Control Processes, no. 4, pp. 43-66, 2013.

[11] O. A. Adesina, "Results on the qualitative behaviour of solutions for a class of third order nonlinear differential equations," AIP Conference Proceedings, vol. 1637, no. 1, pp. 5-12, 2014.

[12] A. U. Afuwape and M. O. Omeike, "Stability and boundedness of solutions of a kind of third-order delay differential equations," Computational and Applied Mathematics, vol. 29, no. 3, pp. 329$342,2010$.

[13] E. N. Chukwu, "On the boundedness and the existence of a periodic solutions of some nonlinear third order delay differential equation," Atti della Academia Nazionale dei Lincei, Classe di Scienze Fisiche, Matematiche e Naturali, vol. 64, no. 5, pp. 440447, 1978.

[14] Z. Gui, "Existence of positive periodic solutions to third order delay differential equations," Electronic Journal of Differential Equations, vol. 91, pp. 1-7, 2006.

[15] M. O. Omeike, "New results on the stability of solution of some non-autonomous delay differential equations of the thirdorder," Differential Equations and Control Processes, vol. 1, pp. 18-29, 2010.

[16] M. O. Omeike, "Uniform ultimate boundedness of solutions of third-order nonlinear delay differential equations," Analele Ştiintifice ale Universităţii “Al.I.Cuza” din Iaşi, Matematica, vol. 56, no. 2, pp. 363-372, 2010.

[17] A. I. Sadek, "Stability and boundedness of a kind of third-order delay differential system," Applied Mathematics Letters, vol. 16, no. 5, pp. 657-662, 2003.

[18] H. O. Tejumola and B. Tchegnani, "Stability, boundedness and existence of periodic solutions of some third order and fourthorder nonlinear delay differential equations," Journal of the Nigerian Mathematical Society, vol. 19, pp. 9-19, 2000.

[19] C. Tunç and H. Ergören, "Uniformly boundedness of a class of non-linear differential equations of third order with multiple deviating arguments," CUBO, vol. 14, no. 3, pp. 63-69, 2012.

[20] C. Tunç and M. Gözen, "Stability and uniform boundedness in multidelay functional differential equations of third order," Abstract and Applied Analysis, vol. 2013, Article ID 248717, 7 pages, 2013.

[21] C. Tunç, "A new result on the stability of solutions of a nonlinear differential equation of third order with finite lag," Southeast Asian Bulletin of Mathematics, vol. 33, pp. 947-958, 2009.

[22] C. Tunç, "Existence of periodic solutions to nonlinear differential equations of third order with multiple deviating arguments," International Journal of Differential Equations, vol. 2012, Article ID 406835, 13 pages, 2012.

[23] C. Tunç, "On existence of periodic solutions to nonlinear third order differential equations with delay," Journal of Computational Analysis and Applications, vol. 12, no. 1, pp. 191-201, 2010. 
[24] C. Tunç, "On the stability and boundedness of solutions of nonlinear third order differential equations with delay," Filomat, vol. 24, no. 3, pp. 1-10, 2010.

[25] C. Tun, "On the qualitative behaviors of solutions to a kind of nonlinear third order differential equations with retarded argument," Italian Journal of Pure and Applied Mathematics, no. 28, pp. 273-284, 2011.

[26] C. Tunç, "Some stability and boundedness conditions for nonautonomous differential equations with deviating arguments," Electronic Journal of Qualitative Theory of Differential Equations, no. 1, pp. 1-12, 2010.

[27] C. Tunç, "Stability and boundedness for a kind of non-autonomous differential equations with constant delay," Applied Mathematics and Information Sciences, vol. 7, no. 1, pp. 355-361, 2013.

[28] C. Tunç, "Stability and boundedness of solutions of nonlinear differential equations of third-order with delay," Differential Equations and Control Processes, no. 3, pp. 1-13, 2007.

[29] H. Yao and J. Wang, "Globally asymptotic stability of a kind of third order delay differential system," International Journal of Nonlinear Science, vol. 10, no. 1, pp. 82-87, 2010.

[30] Y. F. Zhu, "On stability, boundedness and existence of periodic solution of a kind of third order nonlinear delay differential system," Annals of Differential Equations, vol. 8, no. 2, pp. 249259, 1992.

[31] T. A. Ademola, M. O. Ogundiran, P. O. Arawomo, and O. A. Adesina, "Boundedness results for a certain third order nonlinear differential equation," Applied Mathematics and Computation, vol. 216, no. 10, pp. 3044-3049, 2010. 


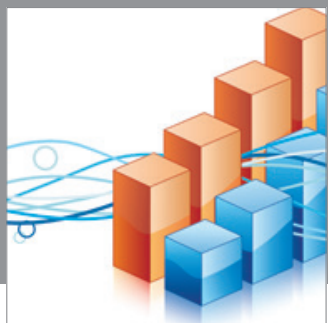

Advances in

Operations Research

mansans

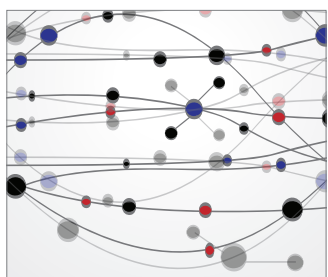

The Scientific World Journal
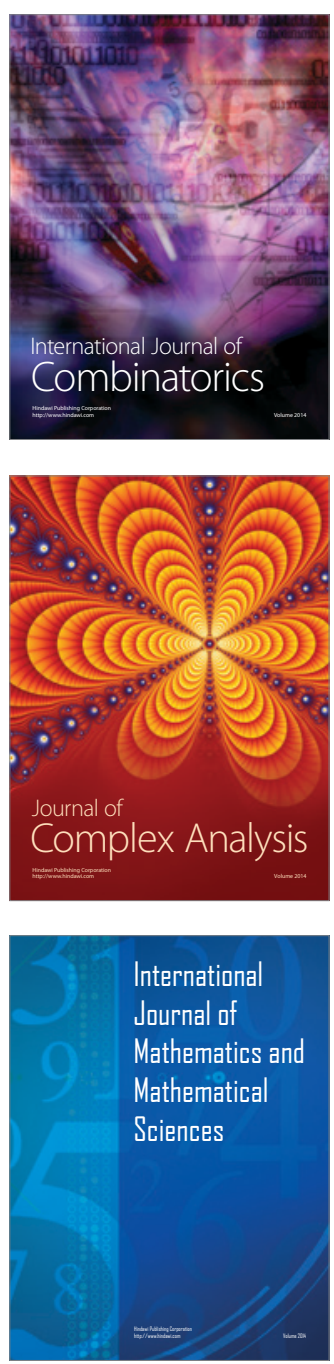
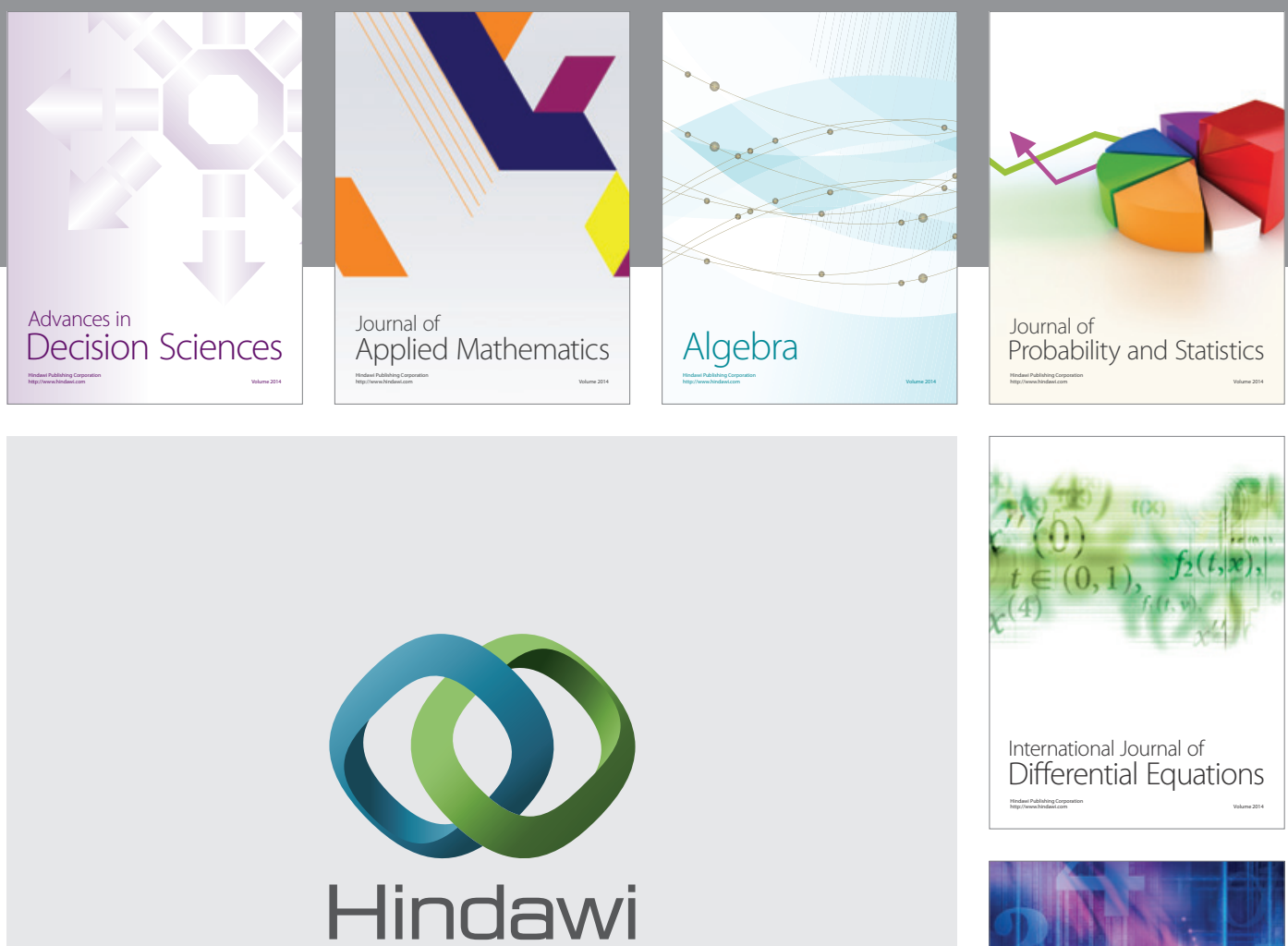

Submit your manuscripts at http://www.hindawi.com
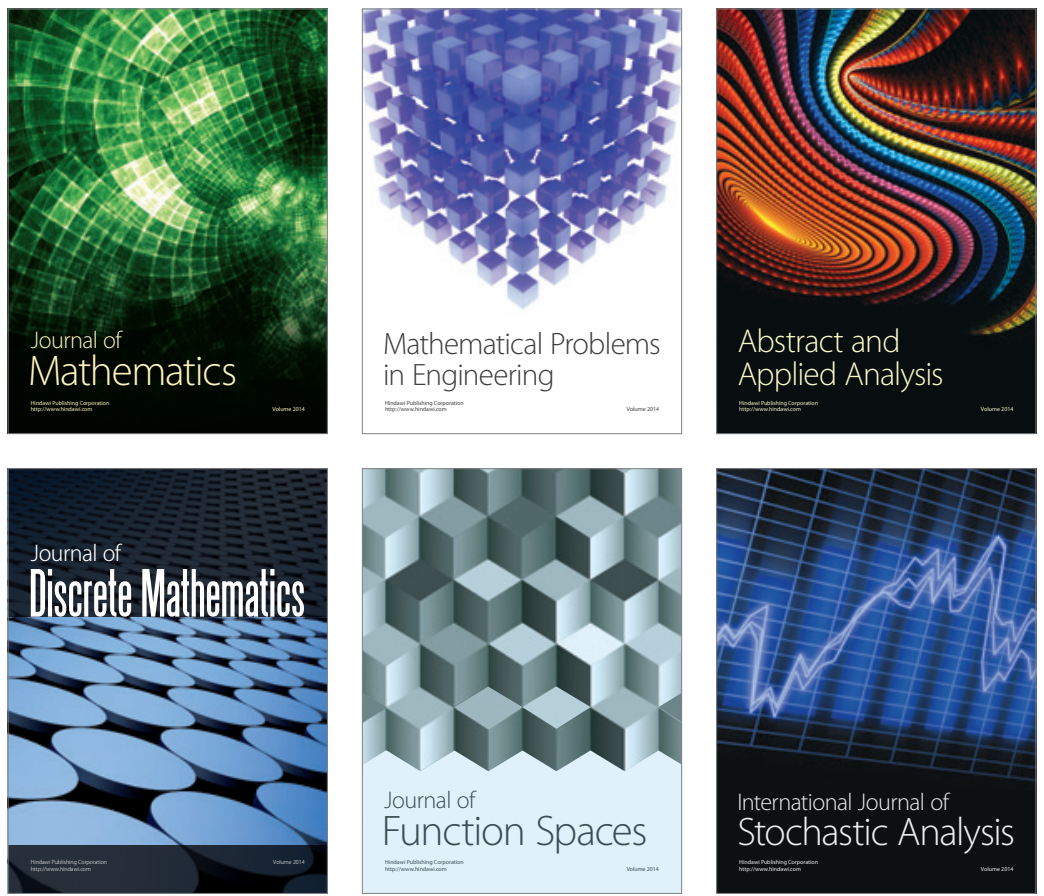

Journal of

Function Spaces

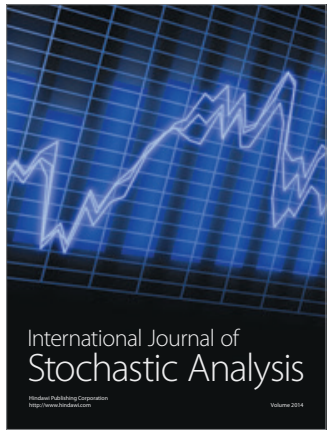

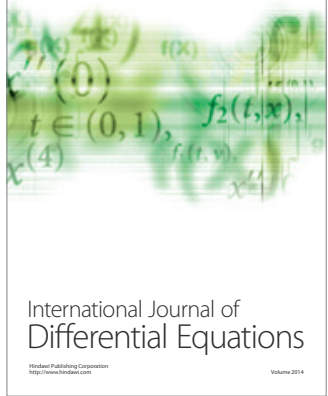
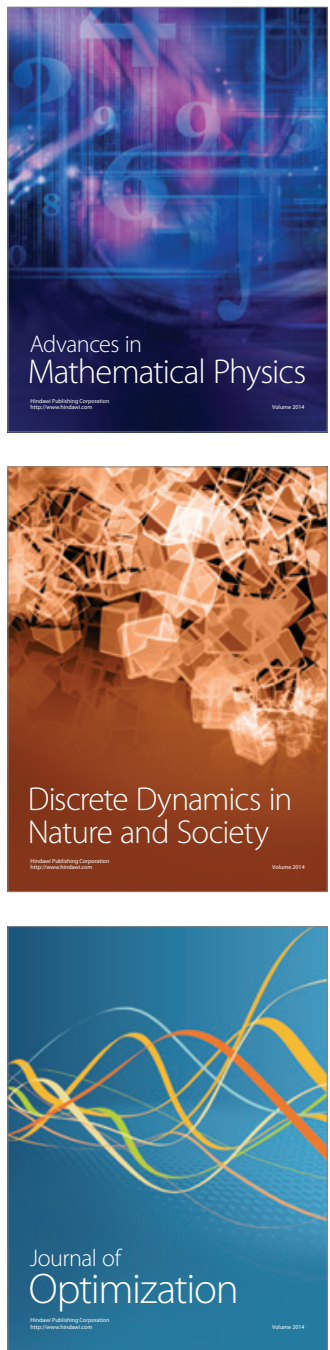